\title{
Medievalista
}

Online

23 | 2018

Número 23

\section{Editorial: Um número especial da Medievalista... dentro da nossa normalidade}

Covadonga Valdaliso Casanova e Francisco José Díaz Marcilla

\section{(2) OpenEdition}

1 Journals

\section{Edição electrónica}

URL: http://journals.openedition.org/medievalista/1564

DOI: 10.4000/medievalista.1564

ISSN: 1646-740X

\section{Editora}

Instituto de Estudos Medievais - FCSH-UNL

Edição impressa

Data de publição: 1 janeiro 2018

\section{Refêrencia eletrónica}

Covadonga Valdaliso Casanova e Francisco José Díaz Marcilla, « Editorial: Um número especial da Medievalista... dentro da nossa normalidade », Medievalista [Online], 23 | 2018, posto online no dia 07 maio 2018, consultado o 23 setembro 2020. URL : http://journals.openedition.org/medievalista/1564 ; DOI : https://doi.org/10.4000/medievalista. 1564

Este documento foi criado de forma automática no dia 23 setembro 2020.

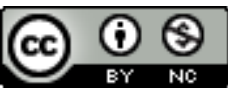

Mediavalista está licenciado com uma Licença Creative Commons - Atribuição-NãoComercial 4.0 Internacional. 


\title{
Editorial: Um número especial da Medievalista... dentro da nossa normalidade
}

\author{
Covadonga Valdaliso Casanova e Francisco José Díaz Marcilla
}

1 O presente número da Medievalista é uma edição especial. Não porque quebre a absoluta regularidade de publicação da revista nem porque se tenha alterado o figurino a que habituou quem nela publica ou quem a consulta. Fiel às nossas exigências também neste campo, o número é disponibilizado na data normal, no início do semestre a que respeita. Mas especial porque, embora discutido e pensado várias vezes, nunca antes fora possível preparar e oferecer um verdadeiro dossier temático. Graças ao trabalho e à colaboração dos organizadores do colóquio "Debuerit habere regnum. Depor e proclamar reis na Idade Média", que teve lugar na Faculdade de Letras de Lisboa entre 12 e 14 de Outubro de 2016, e à disponibilidade de um vasto conjunto de autores, são agora divulgados vários dos trabalhos aí apresentados, depois de submetidos ao processo de avaliação por pares. Trata-se de nove artigos que, após aprovação, desenvolvem as comunicações então apresentadas e formam um excelente corpus de reflexão sobre o tema da deposição e da proclamação de soberanos medievais em diversos reinos e circunstâncias. Os textos aqui incluídos são adiante individualmente apresentados pelos organizadores do referido colóquio, Covadonga Valdaliso Casanova e Francisco José Díaz Marcilla, a quem agradecemos pela proposta que apresentaram à Medievalista e por todo o empenhamento com que participaram na preparação editorial do dossier que agora vem a público. Do mesmo modo, cumpre agradecer aos autores dos artigos por publicarem na nossa revista, dando assim mostras da confiança e do apreço que a Medievalista lhes merece.

2 É também publicado um artigo de Miguel Aguiar cuja temática ("As crónicas de Zurara: a Corte, a Aristocracia e a Ideologia Cavaleiresca em Portugal no século XV") se encontra de algum modo relacionada com o referido dossier. Daí ter-se decidido incluílo neste número. Igualmente presentes estão as habituais secções de Recensões e Apresentação de Teses. 
Uma menção especial para o Destaque, com uma extensa entrevista a Maria Helena da Cruz Coelho. Tomando como pretexto a sua aposentação e as várias homenagens que nessa ocasião lhe foram feitas, a Medievalista entrevistou aquela que é uma historiadora de referência no medievalismo português e com claro reconhecimento além-fronteiras. As respostas constituem não apenas um balanço do que tem sido uma vida dedicada à investigação e ao ensino, mas também um relevante contributo para a reflexão acerca da situação actual dos estudos e dos "usos" da Idade Média entre nós. Destaque merece também o texto de Virgílio Lopes sobre "O Complexo Religioso de Mértola e os Baptistérios de Mértola na Antiguidade Tardia", dando a conhecer novos elementos sobre os trabalhos arqueológicos nesta vila alentejana.

Um "número especial", portanto, que não se afasta da linha científica e da orientação editorial da Medievalista. Uma linha científica que não é de "escola" nem de "capela", procurando definir-se apenas pela busca do rigor; e uma orientação editorial de plena abertura temática, metodológica e linguística, para todos aqueles que queiram ajudar a fazer da Medievalista o que ela sempre quis e quer continuar a ser: um instrumento de verdadeiro acesso aberto para a construção e a divulgação de estudos de qualidade sobre a Idade Média.

\section{“Debuerit habere regnum. A Legitimidade nas Monarquias Medievais"}

5 Embora no testamento de D. Afonso II de Portugal se estabelecesse que o seu filho, Sancho, devia herdar o reino - debuerit habere regnum -, anos mais tarde este monarca foi deposto e morreu exilado em Castela. Poder-se-ia pensar que este episódio isolado não é representativo na história de uma monarquia que, só mais de um século depois, iria viver uma outra irregularidade sucessória, com a proclamação do mestre João de Avis como D. João I. Porém, a instabilidade política em territórios com sistemas de governo monárquicos, como eram em grande parte os medievais, traduzia-se frequentemente em deposições, proclamações e no que hoje chamamos quebras dinásticas. Para alguns períodos da Idade Média basta escolher uma área geográfica para reunir vários exemplos. Em 1359, cinco anos depois de o rei Iúçufe V de Granada ter sido assassinado, o seu filho Maomé $\mathrm{V}$ foi destronado e substituído pelo seu meioirmão, Ismail II, que seria também assassinado, dez meses mais tarde, por ordem do novo monarca, Maomé VI. Em 1362, a cabeça de Maomé VI foi enviada a Maomé V, que recuperou assim a coroa, pelo seu aliado Pedro I de Castela. Em 1366, Henrique de Trastámara, filho ilegítimo de Afonso XI de Castela, autoproclamou-se rei, obrigou o seu meio-irmão, Pedro I, a fugir do reino e, três anos depois, assassinou-o.

6 Os estudos reunidos neste dossier apresentam outros casos de deposições, regicídios e proclamações irregulares, bem como análises de processos de legitimação ou de deslegitimação que envolveram a utilização de vários símbolos e palcos, a construção de discursos propagandísticos e de argumentos jurídicos, a escrita de complexos relatos historiográficos e a elaboração de teorias sobre o tiranicídio. Mostram como a memória de Guilherme II de Inglaterra, o Ruivo, filho de Guilherme o Conquistador, ficou associada ao modelo de mau rei, exemplum daquilo que um soberano não devia ser (Fabrizio De Falco, “Tanto malvagio da essere d'esempio. I clerici anglo-normanni e la descrizione di Guglielmo II Rufo, disgraziatamente re d'Inghilterra"); a forma como o rei Sverre da Noruega utilizou três funerais - os dos seus inimigos e o seu próprio - 
como palco para encenar a propaganda política que iria fazer com que ele e o seu sucessor se mantivessem no poder (David Brégaint, "Staging deaths: King Sverre or a usurper's path to the throne"); as justificações da deposição de Garcia da Galiza, filho dos reis Sancha e Fernando de Leão, e irmão de Sancho II e Afonso VI, que refletem as crónicas dos séculos posteriores (Maria Joana Gomes, "Erat simplicis ingenii: A deposição de Garcia da Galiza vista pelos os cronistas do século XII e XIII"); a fundamentação do tiranicídio e o papel jogado pela nobreza na eleição do novo rei, na primeira crónica escrita em língua checa (Éloïse Adde, "The Justification of Tyrannicide in the Chronicle of Dalimil. The Czech Nobility as the "Mystical Body" of the Realm"); a auto-afirmação dos motivos que levaram o rei Pedro IV de Aragão a depor o rei de Maiorca, Jaime III, em 1349, e a ocupar o trono desse reino, justificando a sua acção através da cronística (Gabriel Ensenyat, "La filosofia discursiva de Pedro el Ceremonioso respecto a la reintegración de la Corona de Mallorca a la Corona de Aragón"); o tratamento propagandístico da imagem do novo rei de Portugal, João I, eleito em 1385, na historiografia redigida pelos inimigos castelhanos (Néstor Vigil, "'El maestre Davis que se fazia llamar rey de Portugal'. La imagen propagandística de D. João I de Portugal en las fuentes castellanas"); as teorias humanistas sobre o tiranicídio utilizadas para justificar o assassinato de Louis d'Orléans, irmão do rei Carlos VII de França (Lucie Jollivet, "Les humanistes français, le roi et le tyran. Débats autour du tyrannicide au sein du milieu humaniste français, $1^{\text {ère }}$ moitié $d u X V^{e}$ siècle"); os mecanismos usados pelo rei eleito da Coroa de Aragão, Fernando I, para fazer propaganda através das cerimônias de entrada nas cidades e de coroação (Víctor Muñoz, “¿Representar la legitimidad? Objetos, símbolos y comunicación en las ceremonias públicas del reinado de Fernando I de Aragón"); e as argumentações jurídicas que aduziram os juristas, aquando da menoridade de $\mathrm{D}$. Afonso $\mathrm{V}$ de Portugal, para negar os direitos à regência de D. Leonor de Aragão, mãe do rei menino (Manuel Ramos, "Mulier ne debuerit habere regnum": a regência na menoridade de D. Afonso V vista pelos juristas").

7 Trata-se de nove artigos, escritos em cinco línguas diferentes por investigadores procedentes de universidades de seis países, que foram selecionados depois de terem passado por dois processos de avaliação. A estes dados, que revelam o carácter internacional do conjunto, bem como a alta qualidade dos textos, devemos acrescentar mais um: os estudos que formam este dossier da Medievalista foram apresentados no Colóquio Internacional "Debuerit habere regnum. Depor e proclamar reis na Idade Média", celebrado entre os dias 12 e 14 de Outubro de 2016 na Faculdade de Letras da Universidade de Lisboa, que acolheu mais de quarenta investigadores, três conferências e quase trinta comunicações. $O$ objetivo desse encontro interdisciplinar foi reunir especialistas em História, Literatura e História da Arte para debater sobre as deposições e as auto-proclamações irregulares de reis medievais, a função dos símbolos monárquicos e o desenvolvimento dos processos de legitimação, o significado das cerimónias régias e das imagens e descrições verbais contemporâneas que se lhes referiam, o valor dos objectos simbólicos associados à monarquia, o conteúdo dos discursos e argumentos utilizados ou criados para legitimar as deposições e as proclamações irregulares, as justificações posteriores e as refutações. Este dossier representa o último capítulo desse debate e a sua plasmação escrita. Resta apenas agradecer a todos os que participaram no Colóquio as suas contribuições como conferencistas, comunicantes, comentadores, presidentes de mesa, avaliadores ou membros das comissões; à revista Medievalista o acolhimento, a simpatia e o laborioso trabalho de avaliação e edição desempenhado; e, aos autores dos textos aqui publicados, 
a confiança depositada neste projeto e a vontade de partilhar os resultados das suas investigações. 